\title{
Kompos cair sebagai Alternatif Pupuk yang Ramah Lingkungan Dalam Produksi Padi
}

\author{
Siti Mudmainah ${ }^{1)}$, Dwi Ari Cahyani²), Purwanto ${ }^{3)}$
}

\begin{abstract}
The development of cheap and easily applied organic fertilizer technology through extraction of fertilizers into liquid organic fertilizer has become one of the simple and inexpensive technological alternatives. The variety of raw materials for making liquid compost will certainly affect nutrient content and useful microbial content. This study was aimed to examine the effect of compost tea from various compost sources enriched with biological agents to improve the growth and yield of rice plants that are cultivated organically. This study used Randomized Complete Block Design with 10 treatments and repeated three times. The treatments tried included $p_{0}$ : control; $p_{1}$ : liquid compost from cow compost; $p_{2}$ : liquid compost from chicken coop compost; $p_{3}$ : liquid compost from mushroom waste; $p_{4}$ : liquid compost from cow compost + Pseudomonas flouresence; $p_{5}$ : liquid compost from compost chicken coop + Pseudomonas flouresence; $\mathrm{p}_{6}$ : liquid compost from waste mushroom + Pseudomonas flouresence; $\mathrm{p}_{7}$ : liquid compost from cow compost + Trichoderma harzianum; p8: compost tea from chicken coop compost + Trichoderma harzianum; $p_{9}$ : liquid compost from waste of mushroom + Trichoderma harzianum. The variables observed included plant height, number of tillers, leaf greenness, leaf area, LAI, number of productive tillers, panicle length, number of seeds per panicle, percentage of filled grain, and grain yield. The results showed that the application of liquid compost enriched with useful microorganisms had not shown its effect in increasing the growth and yield of Sintanur variety in organic cultivation. The highest yield were achieved in the treatment of liquid compost from baglog mushroom enriched with Trichoderma harzianum at 3.06 tons ha-1. $^{-1}$.
\end{abstract}

Keywords : Rice, Liquid Compost Growth, Yield, Organic

\section{PENDAHULUAN}

Kebutuhan beras nasional dan tingginya konsumsi per kapita menuntut pemenuhan produksi sebagai strategi dalam menciptakan ketahanan pangan nasional. Disisi lain, peningkatan kesejahteraan pada strata menengah ke atas dimasyarakat mempunyai pola konsumsi beras yang berbeda, dimana pertimbangan kualitas dan keamanan pangan menjadi pilihan. Golongan masyarakat ini cenderung memilih beras sehat yang diproduksi secara organik sebagai pilihan dalam memenuhi kebutuhan pangan pokoknya. Utami (2011) melaporkan bahwa preferensi konsumen beras organik lebih besar ditentukan oleh motif kesehatan karena kesadaran akan pangan yang sehat dan bahaya residu kimia dalam beras. Permintaan beras organik mengalami peningkatan rata-rata 2,23 persen pertahun, dan kesenjangan antara produksi dan permintaan yang sangat besar (Noviyanto, dan Setyowati, 2009). Purwanto (2009) melaporkan bahwa produktivitas padi yang budidayakan secara organik pada lahan peralihan, mengalami penurunan produksi mencapai 40 persen, dan tingkat produksi tertinggi baru mencapai 4.54 ton ha 1 untuk varietas Mentik Wangi.

Penggunaan pupuk organik dalam produksi padi organik menghadapi masalah terkait sifat bahan yang dengan kandungan hara rendah sehingga menyebabkan

\footnotetext{
1)Fakultas Sains dan Teknologi, Universitas Peradaban Bumiayu

2)Jurusan Agroteknologi, Politeknik Banjarnegara

3)Fakultas Pertanian, Universitas Jenderal Soedirman

Author Contact: nasutionmanis@gmail.com
}

pengadaan, transportasi dan biaya per unit hara yang terkandung cukup mahal, serta pengaruh yang tidak langsung terlihat (Pirngadi, 2009; Syam, 2008). Pengembangan teknologi pupuk organik yang murah dan mudah diaplikasikan melalui pengekstrakan pupuk menjadi pupuk organik cair menjadi salah satu alternative teknologi yang sederhana dan murah. Produk ekstrak kompos dalam bentuk cair disebut sebagai kompos cair. Pembuatan kompos cair dilakukan dengan melarutkan kompos dengan pelarut pada umumnya air baik dengan menggunakan aerasi maupun tidak menggunakan aerasi dan dapat ditambahkan inoculum atau diperkaya dengan mikroorganisme berguna (Martin dan Brathwaite, 2012).

Beragamnya bahan baku untuk membuat kompos cair tentunya akan berpengaruh terhadap kandungan hara dan kandungan mikroba. Menurut Pant et al., (2012) jenis dan kematangan kompos merupakan karakter yang menentukan terhadap nutrisi yang terlarut, asam organik, kadar logam berat, dan kandungan fitotoksik. Fritz et al., (2012) melaporkan bahwa penambahan substrate pada fermentasi kompos cair mampu meningkatkan populasi mikroorganisme berguna dan applikasi vermicompost tea mampu meningkatkan pertumbuhan tanaman gandum dan kacang kapri. Aplikasi kompos cair pada budidaya secara organik dengan penurunan dosis nutrisi setengah dosis dan penyemprotan kompos cair semingggu sekali mampu meningkatkan hasil dan kualitas hasil tanaman melon sebesar 18,3\% (Naidu et al., 2013). Lebih lanjut Siddiqui et al., (2008) melaporkan bahwa pengkayaan kompos cair dengan Trichoderma spp. mampu menekan keparahan penyakit busuk basah Choanephora sampai $85,04 \%$. Penelitian ini bertujuan untuk mengkaji pengaruh kompos cair dari berbagai 
sumber compost yang diperkaya agensia hayati untuk meningkatkan pertumbuhan dan hasil tanaman padi yang dibudidayakan secara organik.

\section{METODE PENELITIAN}

Penelitian ini dilaksanakan di lahan sawah Exfarm Fak. Pertanian UNSOED dan Lab. Agronomi dan Hortikultura Fak. Pertanian UNSOED dari bulan Mei sampai dengan September 2017. Lahan sawah dengan jenis tanah Inseptisol dan tingkat kesuburan tanah sebagaimana tertera dalam Tabel 1.

Penelitian ini menggunakan Rancangan Acak kelompok Lengkap dengan perlakuan sebanyak 10 dan diulang tiga kali. Perlakuan yang dicoba meliputi $p_{0}$ : kontrol; $\mathrm{p}_{1}$ : kompos cair dari kompos sapi; $\mathrm{p}_{2}$ : kompos cair dari kompos kandang ayam; $\mathrm{p}_{3}$ : kompos cair dari limbah jamur merang; $p_{4}$ : kompos cair dari kompos sapi + Pseudomonas flouresence; $\mathrm{p}_{5}$ : kompos cair dari kompos kandang ayam + Pseudomonas flouresence; $\mathrm{p}_{6}$ : kompos cair dari limbah jamur merang + Pseudomonas flouresence; $\mathrm{p}_{7}$ : kompos cair dari kompos sapi + Trichoderma harzianum; $\mathrm{p}_{8}$ : kompos cair dari kompos kandang ayam + Trichoderma harzianum; p9: kompos cair dari limbah jamur merang + Trichoderma harzianum. Total perlakuan yang diperoleh sebanyak 10 perlakuan dan diulang tiga kali sehingga total terdapat 30 unit perlakuan, dan setiap unit perlakuan berukuran 4 meter $x 4$ meter.

Varietas padi yang digunakan adalah Varietas Sintanur, dengan pengelolaan tanaman secara organic tanpa menggunakan pupuk kimia. Benih padi ditanam pada umur 21 hari setelah sebar dengan jarak tanam 20 $\mathrm{cm}$ x $20 \mathrm{~cm}$. Kompos cair dibuat cara fermentasi kompos. Proses pembuatan dilakukan dengan melarutkan kompos dalam pelarut air (1:5 w/v) dan ditambah molase sebanyak $5 \%$. Proses fermentasi dilakukan secara aerob dimana dalam kultur tersebut diberi aerasi udara. Fermentasi dilakukan selama 15 hari, dan kemudian disaring dengan kasa untuk memperoleh kompos cair yang murni. Aplikasi kompos cair dilakukan dengan cara disemprotkan secara merata dengan konsentrasi $10 \%$ dan volume semprot 400 I ha1 . Aplikasi penyemprotan dilakukan pada umur tanaman $15,25,35,45$, dan 55 hari setelah tanam (hst). Variabel yang diamati meliputi tinggi tanaman, jumlah anakan, kehijauan daun, luas daun, LAI, jumlah anakan produktif, panjang malai, jumlah biji per malai, persentase gabah isi, dan hasil gabah (ton ha ${ }^{-1}$ ). Data yang diperoleh dianalisis dengan ANOVA menggunakan software SAS versi 9 , dan apabila berbeda nyata dilanjutkan dengan DMRT pada tingkat kepercayaan 95\%.

Tabel 1 Hasil analisis kesuburan tanah lokasi penelitian

\begin{tabular}{clccl}
\hline No & Parameter & Satuan & Hasil Uji & Kriteria BPT 2005 \\
\hline 1. & Karbon organik & $\%$ & 2,056 & $1-2$ rendah \\
2. & $\mathrm{pH} \mathrm{H} \mathrm{H}_{2} \mathrm{O}$ & & 6,15 & $5,5-6,5$ agak masam \\
3. & $\mathrm{~N}$ tersedia & ppm & 41,664 & \\
5. & $\mathrm{P}_{2} \mathrm{O}_{5}$ tersedia & ppm & 39,240 & $>20$ sangat tinggi \\
6. & $\mathrm{~K}_{2} \mathrm{O}$ tersedia & ppm & 1,447 & $>1$ sangat tinggi \\
\hline
\end{tabular}

Sumber : data primer hasil analisis di Lab. Tanah UNSOED

Tabel 2 Hasil analisis kandungan hara kompos cair

\begin{tabular}{rrrrrrrr}
\hline No & Kode & $\mathrm{P}_{2} \mathrm{O}_{5}$ total $(\mathrm{ppm})$ & C-organik $(\%)$ & $\mathrm{N}$ total $(\%)$ & $\mathrm{K}_{2} \mathrm{O}$ total $(\%)$ & $\mathrm{DHL}(\mathrm{mS})$ & $\mathrm{pH}$ \\
\hline 1. & $\mathrm{P} 1$ & 57,283 & 0,615 & 0.018 & 0,101 & 7,07 & 4,57 \\
2. & P2 & 107,639 & 0,302 & 0,122 & 0,274 & 17,23 & 7,48 \\
3. & P3 & 85,595 & 0,817 & 0,016 & 0,098 & 10,11 & 4,7 \\
4. & P4 & 66,239 & 0,686 & 0,012 & 0,078 & 6,88 & 4,55 \\
5. & P5 & 93,995 & 0,707 & 0,116 & 0,339 & 24,4 & 6,9 \\
6. & P6 & 34,899 & 0,804 & 0,018 & 0,103 & 13,1 & 4,92 \\
7. & P7 & 124,033 & 0,842 & 0,016 & 0,116 & 7,38 & 3,84 \\
8. & P8 & 42,215 & 1,210 & 0,146 & 0,358 & 26,3 & 5,96 \\
9. & P9 & 136,476 & 1,145 & 0,025 & 0,126 & 13,4 & 4,05 \\
\hline
\end{tabular}

Sumber : data primer hasil analisis di Lab. Tanah UNSOED. $p_{0}$ : kontrol; $p_{1}$ : kompos cair dari kompos sapi; $p_{2}$ : kompos cair dari kompos kandang ayam; $p_{3}$ : kompos cair dari limbah jamur merang; $p_{4}$ : kompos cair dari kompos sapi + Pseudomonas flouresence; $\mathrm{p}_{5}$ : kompos cair dari kompos kandang ayam + Pseudomonas flouresence; $\mathrm{p}_{6}$ : kompos cair dari limbah jamur merang + Pseudomonas flouresence; $\mathrm{p}_{7}$ : kompos cair dari kompos sapi + Trichoderma harzianum; $p_{8}$ : kompos cair dari kompos kandang ayam + Trichoderma harzianum; p9: kompos cair dari limbah jamur merang + Trichoderma harzianum.

\section{HASIL DAN PEMBAHASAN}

Aplikasi berbagai jenis kompos cair yang diperkaya dengan agensia hayati menunjukkan hasil bahwa kompos cair baik dari berbagai bahan maupun yang diperkaya dengan agensia hayati belum menunjukkan pengaruh terhadap variable tinggi tanaman maupun jumlah anakan sampai umur 61 hari setelah tanam (hst) sebagaimana terlihat pada Gambar 1. Variasi tinggi tanaman maupun jumlah anakan pada berbagai jenis kompos cair yang diperkaya Pseudomonas flouresence maupun Trichoderma harzianum tidak menunjukkan variasi yang tinggi. Variasi tinggi tanaman pada rentang $61,29 \mathrm{~cm}$ pada perlakuan kompos cair dari kompos kandang sapi (P1) sampai 70,11 cm pada perlakuan kompos cair yang berasal dari kompos kandang ayam 
(P2). Variasi jumlah anakan total sampai umur 61 hst cenderung bervariasi antar perlakuan dimana jumlah anakan terbanyak diperoleh pada perlakuan kompos cair yang berasal dari kompos baglog jamur merang.

Variabel tinggi tanaman dan jumlah anakan merupakan variable pertumbuhan yang sangat dipengaruhi oleh kondisi lingkungan tumbuh tanaman terutama kadar hara tanah. Hal ini terlihat bahwa kadar hara nitrogen tersedia pada tanah yang digunakan sebagai lahan penelitian menunjukkan kadar sebesar 41,667 ppm, dan kadar $\mathrm{P}_{2} \mathrm{O}_{5}$ maupun $\mathrm{K}_{2} \mathrm{O}$ termasuk dalam kategori tinggi masing masing sebesar 39,340 ppm, dan 1,447 ppm (Tabel 1).

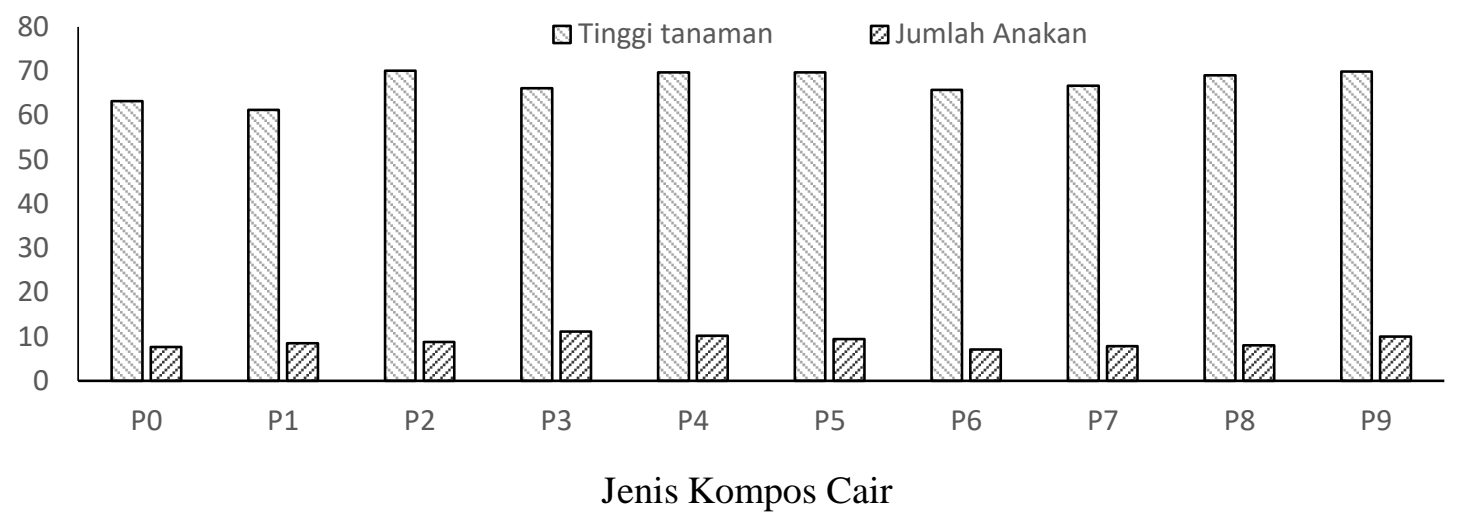

Gambar 1. Tinggi tanaman dan jumlah anakan tanaman padi pada perlakuan kompos cair

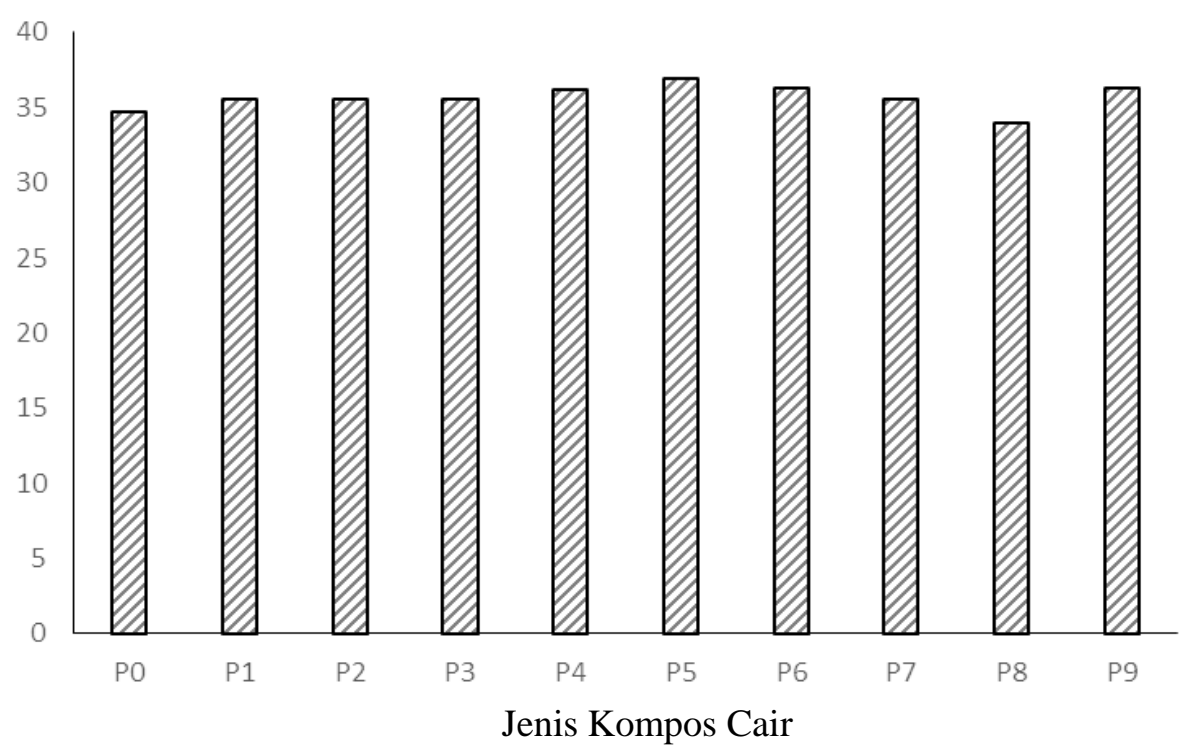

Gambar 2. Kehijauan daun (SPAD unit) tanaman padi pada berbagai perlakuan kompos cair

Kadar hara makro yang tinggi terutama hara NPK diduga mampu mensuplai kebutuhan hara tanaman padi sehingga penambahan kompos cair sebagai pupuk daun belum menunjukkan pengaruh yang nyata terhadap variable pertumbuhan. Hal ini juga terlihat pada variabel kehijauan daun, luas daun dan indeks luas daun, dimana perlakuan kompos cair belum menunjukkan pengaruh yang nyata. Sebagaimana diketahui bahwa daun merupakan sebagai sumber dalam metabolism tanaman dimana reaksi fotosintesis terjadi dengan adanya klorofil dan cahaya matahari.

Variabel kehijauan daun menunjukkan jumlah total klorofil dalam daun. Hal ini sesuai dengan hasil penelitian Purwanto (2009) yang menunjukkan bahwa adanya korelasi yang nyata antara nilai kehijauan daun (nilai SPAD) dengan kadar klorofil total a, b maupun klorofil total tanaman padi. Hasil penelitian menunjukkan bahwa nilai kehijauan daun pada berbagai kompos cair yang diperkaya dengan Pseudomonas flouresence maupun Trichoderma harzianum berada pada nilai diatas 30 SPAD unit. Hal ini menunjukkan bahwa tanaman padi kebutuhan haranya telah terpenuhi terutama hara nitrogen. Menurut Syafrudin et al., (2008) kadar klorofil dan nilai SPAD daun berkorelasi dengan kadar $\mathrm{N}$ daun berkorelasi nyata seiring meningkatnya umur pada tanaman jagung. Lebih lanjut Suminarti (2010) menyatakan bahwa tanaman yang mengandung $\mathrm{N}$ rendah, kadar klorofil daun juga menunjukkan kadar yang rendah. Hal ini akan berdampak terhadap laju metabolism tanaman terutama proses fotosintesis. Klorofil mempunyai kemampuan dalam menyerap gelombang elektromagnetik dari spectrum cahaya matahari dan menampung cahaya yang diserap untuk proses fotosintesis (Ai dan Banyo, 2011). 


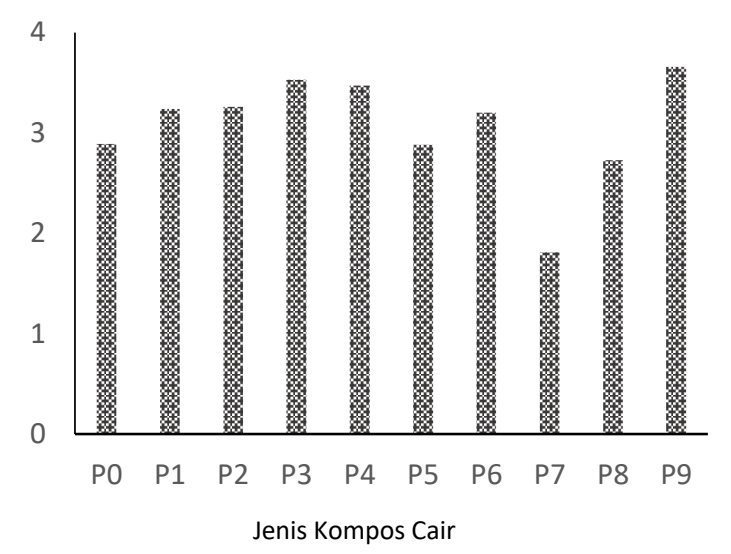

a. Indeks Luas Daun

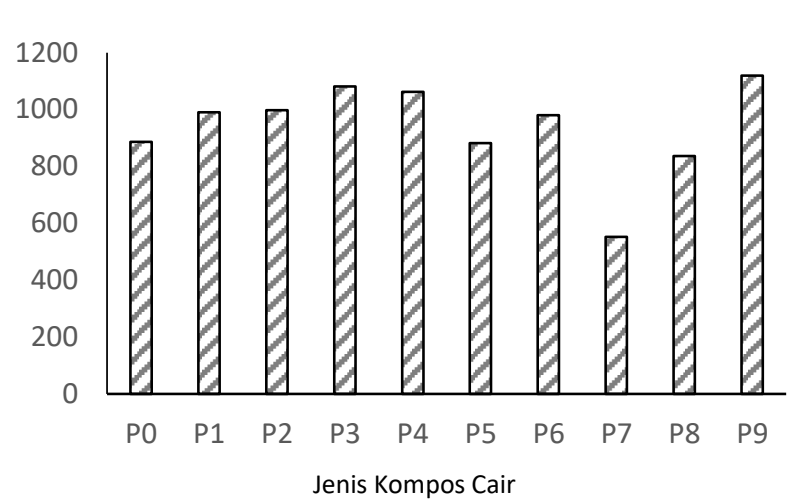

b. Luas Daun $\left(\mathrm{cm}^{2}\right)$

Gambar 3. Luas daun dan indeks luas daun tanaman padi pada berbagai perlakuan kompos cair

Aplikasi compost tea yang diperkaya mikroorganisme berguna baik Pseudomonas flouresence maupun Trichoderma harzianum belum menunjukkan pengaruhnya terhadap variable luas daun dan indek luas daun. Kisaran luas daun $552,79 \mathrm{~cm}^{2}$ pada perlakuan kompos cair kompos sapi + Trichoderma harzianum dan tertinggi pada perlakuan kompos cair limbah baglog jamur + Trichoderma harzianum sebesar $1120,14 \mathrm{~cm}^{2}$. Besarnya nilai luas daun tanaman berkorelasi dengan besarnya nilai Indeks Luas Daun (ILD) tanaman padi, dimana ILD tertinggi dicapai pada perlakuan kompos cair limbah baglog jamur + Trichoderma harzianum sebesar 3,66. Pertumbuhan daun tanaman akan meningkat dengan sampai pada suatu titik menurut ontogeny tanaman (Garder et al., 1991). Factor hara merupakan salah satu factor yang mempengaruhi perluasan daun terutama hara N. Pada penelitian ini, aplikasi kompos cair diduga belum mampu meningkatkan suplai hara melalui daun, disamping itu lahan yang digunakan memiliki kadar hara NPK yang

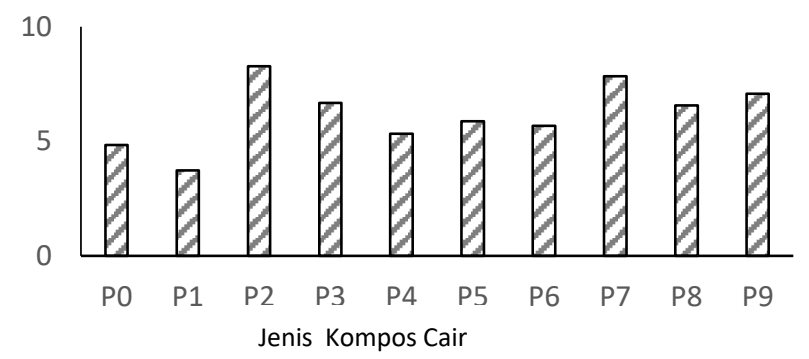

a. Jumlah anakan produktıt

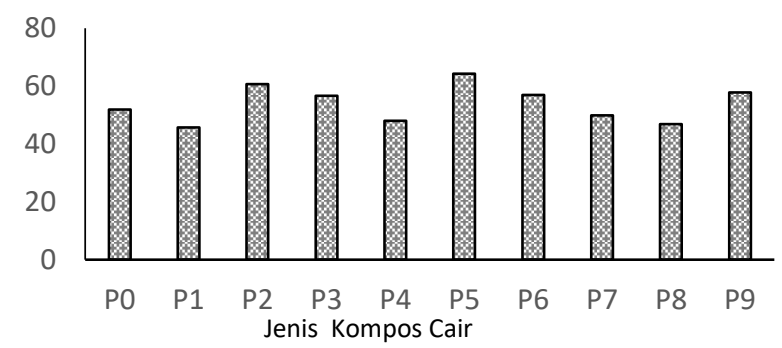

c. Jumlah gabah per malai tinggi. Pengelolaan lahan dengan penggenangan diduga mampu meningkatkan ketersediaan hara. Penggenangan lahan akan meningkatkan $\mathrm{pH}$ dan ketersediaan hara $\mathrm{P}$ bagi tanaman. Disamping itu, pengkayaan Trichoderma harzianum disamping sebagai agensia hayati juga berperan dalam proses pelarutan Fosfat tanah.

Komponen hasil dan hasil tanaman belum menunjukkan variasi hasil yang berbeda antar perlakuan kompos cair baik yang diperkaya agensia hayati maupun tidak. Variable jumlah anakan produktif, panjang malai, jumlah gabah per malai, maupun bobot seribu biji tidak menunjukkan perbedaan yang nyata antar perlakuan. Hasil tanaman dalam bentuk gabah kering giling (GKG), antar perlakuan kompos cair belum menunjukkan perbedaan yang nyata. Hasil gabah kering giling berkisar antara 2,21 ton ha-1 sampai 3,06 ton ha- ${ }^{-1}$. Hasil gabah kering giling tertinggi dicapai pada perlakuan kompos cair dari baglog jamur yang diperkaya dengan Trichoderma harzianum (Gambar 5).

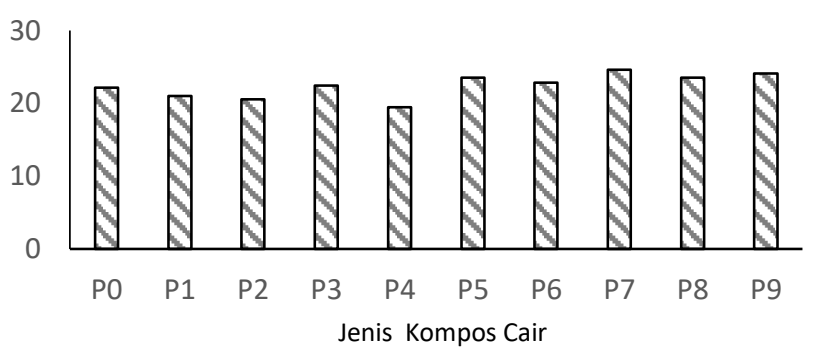

b. Paniang malai $(\mathrm{cm})$

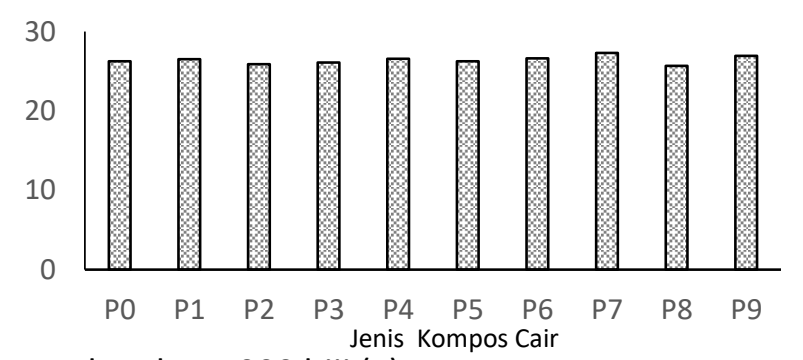

d. Bobot 1000 biji (g)

Gambar 4. Komponen hasil tanaman padi pada berbagai perlakuan kompos cair 


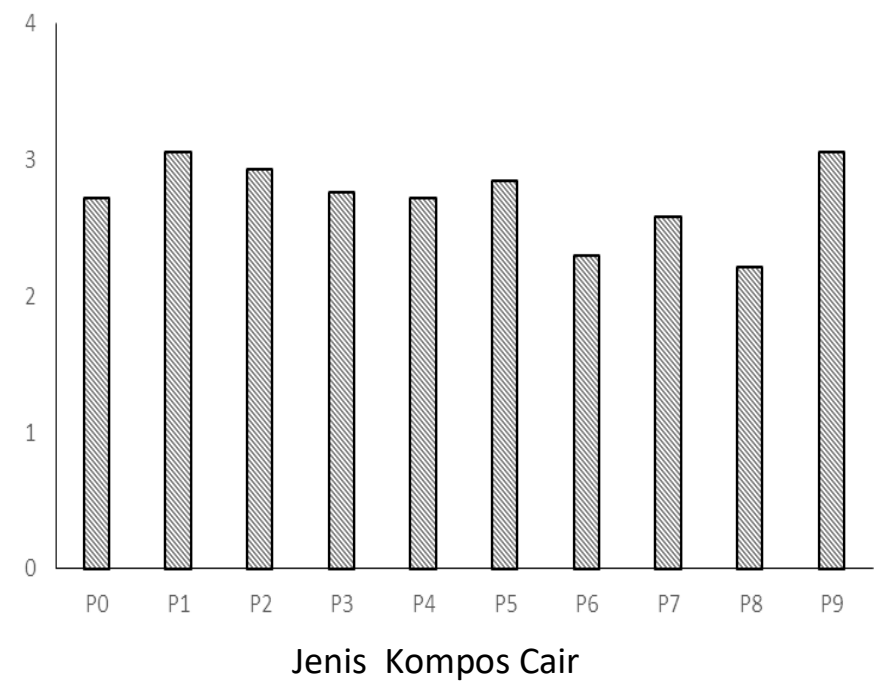

Gambar 5. Hasil gabah kering giling (ton ha- ${ }^{-1}$ ) tanaman padi pada berbagai perlakuan kompos cair

\section{KESIMPULAN}

Aplikasi kompos cair yang diperkaya dengan mikroorganisme berguna baik Pseudomonas flouresence maupun Trichoderma harzianum belum menunjukkan pengaruhnya dalam meningkatkan pertumbuhan dan hasil tanaman padi varietas Sintanur dalam budidaya secara organic. Hasil tertinggi dicapai pada perlakuan kompos cair baglog jamur yang diperkaya dengan Trichoderma harzianum sebesar 3,06 ton ha-1.

\section{DAFTAR PUSTAKA}

Ai, N.S. dan Yunia Banyo. 2011. Konsentrasi klorofil daun sebagai indikator kekurangan air pada tanaman. Jurnal IImiah Sains 11(2): 166-172.

Fritz, J.I., I.H. Franke-Whittle, S. Haindi, H. Insam, and R. Braun. 2012. Microbiological community analysis of vermicompost tea and its influence on the growth of vegetables and cereals. Can. J. Microbiol 58: 836-847.doi: 10.1139/W2012-061.

Gardner, F.P., R.B. Pearce, dan R.L. Mitchell.1991. Fisiologi Tanaman Budidaya. Penerbit Universitas Indonesia, Jakarta.
Martin, C.C.G. St. and R.A.I. Brathwaite. 2012. Compost and compost tea: Principles and prospects as substrates and soil-borne disease management strategies in soil-less vegetable production. Biological Agriculture \& Horticulture 28(1): 1-33. doi: 10.1080/01448765.2012.671516.

Naidu, Y., S. Meon, and Y. Siddique. 2013. Foliar appliacation of microbial-enriched compost tea enhances growth, yield and quality of muskmelon (Cucumis melo L.) cultivated under fertigation system. Scientia Horticulture 159: 33-40.doi : 10.1016/j.scienta.2013.04.024.

Novianto, F.W., dan E. Setyowati. 2009. Analisis produksi padi organik di kabupaten sragen tahun 2008. Jurnal Ekonomi Pembangunan 10(2): 267 288.

Pirngadi, K. 2009. Peran bahan organik dalam peningkatan produksi padi berkelanjutan mendukung ketahanan pangan nasional. Pengembangan Inovasi Pertanian 2(1): 48-64.

Purwanto. 2009. Pertumbuhan dan hasil empat varietas padi pada system pertanian organic, semiorganik, dan konvensional. Thesis. UGM, Yogyakarta (Tidak dipublikasikan).

Siddique, Y., S. Meon, M.R. Ismail, and A. Ali. 2008. Trichoderma-fortified compost extracts for the control of choanephora wet rot in okra production. Crop Protection 27: 385-390. Doi: 10.1016/j.cropro.2007.07.002.

Syam, M. 2008. Padi organik dan tuntutan peningkatan produksi beras. Iptek Tanaman Pangan 3(1): 1-8.

Syafruddin, S. Saenong, dan Subandi. 2008. Penggunaan bagan warna daun untuk efisiensi pemupukan $\mathrm{N}$ pada tanaman jagung. Penelitian Pertanian Tanaman Pangan. 27(1): 24-31.

Utami, D.P., 2011. Analisis pilihan konsumen dalam mengkonsumsi beras organik di Kabupaten Sragen. Mediagro 7(1): 41-58. 